\title{
Thermodynamic modeling of combustion process of the internal combustion engines - an overview
}

\begin{abstract}
The mathematical description of combustion process in the internal combustion engines is a very difficult task, due to the variety of phenomena that occurring in the engine from the moment when the fuel-air mixture ignites up to the moment when intake and exhaust valves beginning open. Modeling of the combustion process plays an important role in the engine simulation, which allows to predict incylinder pressure during the combustion, engine performance and environmental impact with high accuracy. The toxic emissions, which appears as a result of fuels combustion, are one of the main environmental problem and as a result the air pollutant regulations are increasingly stringent, what makes the investigation of the combustion process to be a relevant task.
\end{abstract}

Key words: thermodynamic combustion model, internal combustion engine, convective heat transfer coefficient, Wiebe burning law, single-zone model, two-zone model, heat transfer submodel

\section{Introduction}

The combustion process in the internal combustion engines is a chemical reaction between the fuel and oxidant, with the emission of heat and light. Explosive combustion in a closed volume is one of the most complex and complicated phenomena that are modeled mathematically. The aim of the combustion process modeling is to determine operational parameters and the impact from the engine to the environment.

Increasing of the stringent regulations [6-8] that are aimed to lowering toxic emissions during the ICE combustion process with simultaneously maintaining the high efficiency of engine operation conditions and lowering the fuel consumption, provides to continuous investments, related with the engine development.

Computer modeling and simulation are important tools that are used for obtaining optimal engine designs and allowing significantly reduce time and cost constraint, that are needed for making modifications in existing and/or creating new design solutions of ICE. The existing computational methods and computer programs that are most commonly used for modeling processes that are occurring inside ICE can be divided into two main categories: thermodynamic models (the whole cylinder is considered as one cell. For this cell applies the mass, the energy and the state balance equations) and Computational Fluid Dynamic (CFD) models (engine elements are divided into a high number (hundreds of thousands) of three-dimensional cells and for each of them solved the systems of energy, mass, momentum and state balance equations. This model provides three-dimensional modeling of gas flow and fuel injection into cylinder and/or engine manifold, turbulent mixing of fuel with air, evaporation of fuel-air mixture, ignition and combustion processes. However, this leads to a higher computational time and requires a lot of computing power from the computers). CFD models are most commonly used when the detailed analysis of phenomena that is occurring inside the cylinder during combustion is needed.

Thermodynamic combustion models (TCM) cannot provide analysis with same prediction as CFD. However, TCM are able to predict the combustion process under various engine operating conditions with the required level of accuracy, which is confirmed by many researchers (examples are given in the section below). Based on the number of zones into which the cylinder volume can be divided, thermodynamic models can be classified into three subgroups: single-zone model, two-zone model and multi-zone model.

The choice of the calculation method (CFD or TCM) is based on the main aim of modeling and simulation. However, the thermodynamic models are more attractive, due to lower computational complications and time needed for the calculating of the combustion process. In the case of complex mathematical models, most often used a combination of TCM and CFD methods, for examples the firms which are leaders in calculating engine parameters such, as RICARDO WAVE [24] and AVL BOOST [1] provide the ability to simulate a TCM with combination of CFD model (used to describe the gas flow in three dimensions inside the intake and exhaust manifolds $[5,11,12])$. Due to the fact, that the 3D mesh is limited to specific elements of the intake and/or exhaust manifolds, this allows to minimize the unavoidable increases of the time consuming during the calculation of the engine operating parameters associated with using of CFD models.

This paper discusses the selected issues that are most often described when a single-zone or a twozone thermodynamic combustion model is using.

Multi-zone thermodynamic models in this paper are presented only as a brief overview, because the overview of this models requires individual paper to 
describe all features and properties. This models are quite accurately described in $[3,10,16,30]$.

\section{Thermodynamic model}

In the TCM the internal combustion engine is represented as an open thermodynamic system (singlezone model) or a combination of several thermodynamic systems (two- or multi- zone model).

The fast pressure equalization speed in the relatively small volume (engine cylinder) expect that the pressure inside the cylinder depends on time $(\tau)$ or crankshaft angle $(\varphi)$ (Eq. 1) and does not depend on $\mathrm{x}$, $y, z$ coordinates [16], therefore, the thermodynamic model is considered as a zero-dimensional model

$$
\varphi=\omega \cdot \tau
$$

According to the assumptions above, it can be concluded that TCM - is used for energy analysis of the combustion process in the entire volume of the ICE cylinder and solves the issues in which can be assumed that the gas parameters are independent of coordinates and depend only on the time (or crankshaft angle), also the usage of TCM allows to analyze toxic emission during the combustion process.

In terms of CFD, the TCM represent the entire cylinder as one cell for which are applied the equations of mass, energy and state balance.

Thermodynamic models are used to solve two main issues:

1. Direct issue. Determination of the pressure change inside the cylinder as a function of the crankshaft angle $p(\varphi)$, based on the previously defined amount of energy released during the combustion of the fuel charge $\mathrm{Q}_{\mathrm{x}}(\varphi)$ and heat transfer through the walls $\mathrm{Q}_{\mathrm{w}}(\varphi)$.

2. Reverse issue. Determination the amount of heat energy generated during the combustion of the fuel charge $\mathrm{Q}_{\mathrm{x}}(\varphi)$, based on the previously defined pressure inside the cylinder $\mathrm{p}(\varphi)$, which obtained from experimental data or from the computer simulation. Also needed to define heat transfer through the walls $\mathrm{Q}_{\mathrm{w}}(\varphi)$, if only one pressure is defined than can be determined only amount of total heat $\mathrm{dQ}$, according to Eq. 2

$$
\mathrm{dQ}=\mathrm{dQ}_{\mathrm{x}}-\mathrm{dQ}_{\mathrm{w}}
$$

In order to create TCM, must be solved three equations which are depending on the TCM type.

General equations:

1. The first law of thermodynamics used to describe the processes occurring in the combustion chamber consists in the fact that the change of internal energy in the cylinder is equal to the sum of the work of the piston, the amount of heat and enthalpy in- or out-flowing gas (Eq. 3).
The first law of thermodynamics for the ICE can be defined as

$$
\mathrm{dU}=\mathrm{d}(\mathrm{u} \cdot \mathrm{m})=\mathrm{dQ}-\mathrm{dW}+\mathrm{dH}
$$

2. The ideal gas law

$$
\mathrm{pV}=\mathrm{mRT}
$$

3. Mass conservation law

$$
\mathrm{dm}=\sum \mathrm{dm}_{\mathrm{i}}
$$

\subsection{TCM basic assumptions}

Regardless to the model type, the basic assumptions are the same (differences in model assumptions presented in the relevant parts of this paper):

a) The thermodynamic parameters and composition of the working medium at any moments are homogeneous and stoichiometric and changing only with the crankshaft angle or time.

b) The initial temperature conditions are calculated by means of the perfect gas equation based on the measured pressure, mass of the mixture that is entered into the combustion chamber and the volume of the combustion chamber. The mass of air is measured by using a MAP (manifold absolute pressure) or MAF (mass air flow) sensor, the mass of the fuel is calculated by using a measured air-fuel ratio

$$
\mathrm{AFR}=\frac{\mathrm{m}_{\text {air }}}{\mathrm{m}_{\text {fuel }}}=\frac{\mathrm{n}_{\text {air }} \cdot \mathrm{MW}_{\text {air }}}{\mathrm{n}_{\text {fuel }} \cdot \mathrm{MW}_{\text {fuel }}}
$$

c) Blow-by mass $\left(\mathrm{m}_{\mathrm{BB}}\right)$ of the air to fuel mixture is so small compared to the other masses that are taken into account in the mass conservation law calculation. In the simplest TCM the air to fuel mixture losses by leakage in the piston rings and valves does not taken into account. Of course, depending on the model requirements, the blow-by mass could be taken into account (Eq. 31 and Eq. 32).

d) The heat transfer area is limited by the cylinder head, the top surface of the piston and the cylinder wall.

\section{Thermodynamic submodels}

\subsection{Thermodynamic properties}

To estimate the thermodynamic properties of the gas (variations of specific heat, enthalpy and entropy with temperature) in the cylinder as a function of temperature can be calculated by the well known linear or polynomial Eq. 7, Eq. 8 and Eq. 9, based on the polynomial tables of JANAF.

Instantaneous gas properties are calculated by the simultaneous numerical integration of differential equations

$C p_{i}(T)=R\left(a_{1}+a_{2} T+a_{3} T^{2}+a_{4} T^{3}+a_{5} T^{4}\right)$ 


$$
\begin{aligned}
& \mathrm{hp}_{\mathrm{i}}(\mathrm{T})=R\left(\mathrm{a}_{1}+\mathrm{a}_{2} \frac{\mathrm{T}}{2}+\mathrm{a}_{3} \frac{\mathrm{T}^{2}}{3}+\mathrm{a}_{4} \frac{\mathrm{T}^{3}}{4}+\mathrm{a}_{5} \frac{\mathrm{T}^{4}}{5}+\frac{\mathrm{a}_{6}}{\mathrm{~T}}\right) \\
& \mathrm{S}(\mathrm{T})=\mathrm{R}\left(\mathrm{a}_{1} \cdot \ln \mathrm{T}+\mathrm{a}_{2} \mathrm{~T}+\mathrm{a}_{3} \frac{\mathrm{T}^{2}}{2}+\mathrm{a}_{4} \frac{\mathrm{T}^{3}}{3}+\mathrm{a}_{5} \frac{\mathrm{T}^{4}}{4}+\mathrm{a}_{7}\right)
\end{aligned}
$$

\subsection{The cylinder volume submodel}

The total cylinder volume $(\mathrm{V}(\varphi))$ is the sum of the volumes of the combustion chamber $\left(\mathrm{V}_{\mathrm{c}}\right)$ and the cylinder volume $\left(\mathrm{V}_{\mathrm{s}}\right)$, and depends on the instantaneous position of the piston. The Eq. 10 is based on the kinematic and kinetic of crankshaft as shown in Fig. 1, and can be written as

$$
\mathrm{V}(\varphi)=\mathrm{V}_{\mathrm{c}}+\mathrm{V}_{\mathrm{s}}(\varphi)
$$

The combustion chamber volume

$$
\mathrm{V}_{\mathrm{c}}=\frac{\mathrm{V}_{\mathrm{s}}}{\varepsilon-1}
$$

The instantaneous volume of the cylinder can be calculated on a per-anglestep basis using the following equation

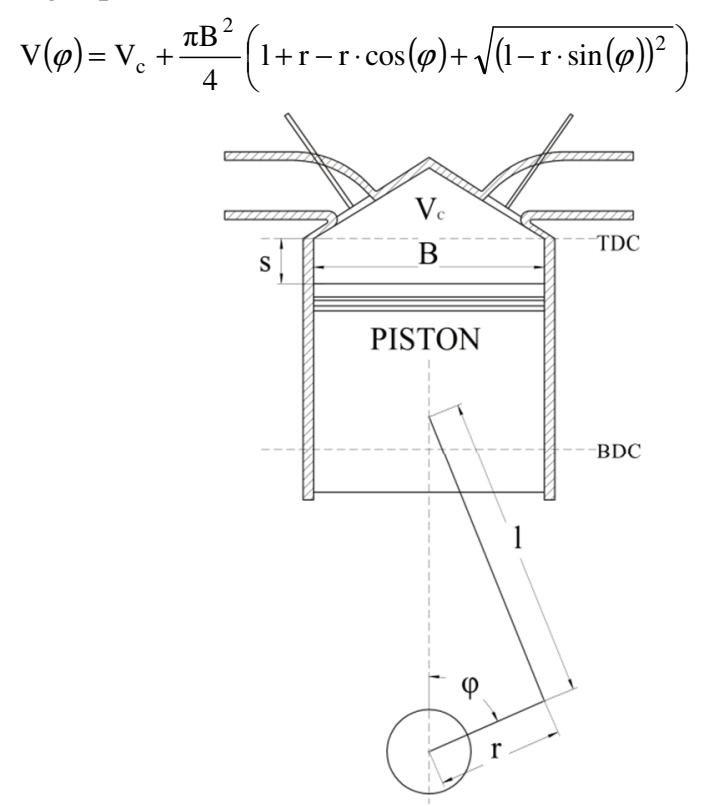

Fig. 1. Schematics of crank mechanism

The piston position is calculated using a standard crank/slider calculation as shown below. As default 0 deg refers to the piston position at top dead centre

$$
\mathrm{S}_{\mathrm{p}}=\left(1+\mathrm{r}-\mathrm{r} \cdot \cos (\varphi)+\sqrt{(1-\mathrm{r} \cdot \sin (\varphi))^{2}}\right)
$$

Cylinder volume change $\left(\mathrm{V}_{\mathrm{s}}(\varphi)\right)$ in the differential form, can be written as

$$
\frac{\mathrm{dV}}{\mathrm{d} \varphi}=\frac{\pi \mathrm{B}^{2}}{4}\left(\mathrm{r} \cdot \sin (\varphi)+\frac{\mathrm{r}^{2} \cdot \sin (\varphi) \cdot \cos (\varphi)}{\sqrt{1^{2}-\mathrm{r}^{2} \cdot \sin (\varphi)}}\right)
$$

\subsection{Heat transfer submodel}

One of the most important submodels of TCM is a heat transfer, this submodel predict a heat transfer from a closed volume (cylinder) to the walls representing as a cylinder head, cylinder liner, top surface of the piston and valve head areas located in the combustion chamber. There are three different types of heat transfer: diffusion, convection and radiation. In this work, only the convective heat transfer was described.

Basically, the heat transfer calculation does not require high computing power. To calculate the amount of heat transferred to the walls, used the NewtonRichman law, that can be written, as

$$
\mathrm{dQ}_{\mathrm{w}}=\alpha_{\mathrm{w}} \mathrm{A}_{\mathrm{w}}\left(\mathrm{T}-\mathrm{T}_{\mathrm{w}}\right) \mathrm{dt}
$$

According to Eq. 15 the heat transfer depends on time, in order to obtain connection with TCM, the Eq. 15 must be dependence on the crankshaft angle. The simplest conversion between time $(\mathrm{t})$ and crankshaft angle $(\varphi)$, can be written as

$$
\mathrm{dt}=\frac{\mathrm{d} \varphi}{6 \mathrm{n}}
$$

where: $\mathrm{t}-$ is expressed in $(\mathrm{s}), \mathrm{n}-$ is expressed in $(\mathrm{rpm}), \varphi-$ is expressed in (deg).

The most important parameter of the heat transfer submodel is the heat transfer coefficient $\left(\alpha_{\mathrm{w}}\right)$.

There are many semi-empirical equations used to predict heat transfer coefficient, the most popular equations in the point of view of the prediction accuracy are Woschni's, Hohenberg's and Annand's equations.

a) Woschni heat transfer coefficient

The Woschni's correlation is well-known and widely used for calculation the heat transfer coefficient in both SI and Diesel engines and is given by Eq. 17. While the other correlations consider the gas velocity to be constant during the engine cycle, the Woschni's correlations provides the most detailed approach in the estimation of convective heat transfer and takes into account the gas velocity increases in the cylinder during the combustion, but the usage of this correlation without calibration often does not allow to calculate the instant heat transfer coefficient with required accuracy

$$
\alpha_{\mathrm{w}}=130 \frac{\mathrm{p}^{0,8} \mathrm{w}^{0,8}}{\mathrm{~T}^{0,52} \mathrm{~B}^{0,2}}
$$

The value of the in-cylinder gas velocity depending on the working period of engine and can be calculated from the Eq. 18 and Eq. 19.

During the gas exchange and compression period

$$
\mathrm{w}=2,28 \cdot \mathrm{C}_{\mathrm{m}}
$$


During the combustion period

$$
\mathrm{w}=2,28 \cdot \mathrm{C}_{\mathrm{m}}+3,34 \cdot 10^{-3} \cdot \frac{\mathrm{V}_{\mathrm{c}} \mathrm{T}}{\mathrm{pV}} \cdot\left(\mathrm{p}-\mathrm{p}_{\mathrm{c}}\right)
$$

Mean piston speed $\left(\mathrm{C}_{\mathrm{m}}\right)$, given by

$$
\mathrm{C}_{\mathrm{m}}=\frac{\mathrm{S}_{\mathrm{p}} \cdot \mathrm{n}}{30}
$$

where: $\mathrm{n}$ - is expressed in [rpm].

Woschni's heat transfer coefficient included the pressure difference between fired and motored operation $\left(p-p_{c}\right)$ in the characteristic velocity to account for the effect of the combustion on the heat transfer [4].

b) Hohenberg heat transfer coefficient

According to Hohenberg, Woschni's correlation underestimates the heat transfer coefficient during compression and overestimates it during combustion. In addition, he stressed its difficulty of use [9]. Based on Woschni's work, Hohenberg proposed the correlation given by Eq. 21

$$
\alpha_{\mathrm{w}}=130 \cdot \mathrm{p}^{0.8} \cdot \mathrm{T}^{-0.4} \cdot \mathrm{V}^{-0.06} \cdot\left(\mathrm{C}_{\mathrm{m}}+1.4\right)^{0.8}[4,9]
$$

c) Annand heat transfer coefficient

Unlike the previous two that were created for Diesel engines and afterwards, adapted for the SI ones, Annand's correlation originated from tests with SI engines [9]. The heat transfer coefficient is evaluated as shown in Eq. 22. Annand's correlations consider the gas velocity to be constant during the engine cycle equal to mean piston speed $\left(\mathrm{C}_{\mathrm{m}}\right)$

$$
\alpha_{w}=c \frac{k_{g}}{D} \cdot R^{0,7}+4,3 \cdot 10^{-9} \cdot\left(\frac{T^{4}-T_{w}^{4}}{T-T_{w}}\right)
$$

where: c - Annand's correlations parameter for a twostroke engine often equal to 0.26 and for four-stroke engine equal to 0.49 .

The second term of Eq. 22 accounts the radiation influence, which most often is neglected for SI engines [9].

\subsection{Combustion submodel}

The combustion duration is described by the amount of energy that released due to the combustion of the charge $\left(Q_{x}\right)$ and can be written, as

$$
\frac{\mathrm{dQ}_{\mathrm{x}}}{\mathrm{d} \varphi}=\mathrm{Q}_{\mathrm{t}} \cdot \frac{\mathrm{dx}_{\mathrm{b}}}{\mathrm{d} \varphi}
$$

Total thermal energy of the fuel released during the combustion process $\left(Q_{t}\right)$, given by

$$
\mathrm{Q}_{\mathrm{t}}=\mathrm{m}_{\text {fuel }} \cdot \mathrm{LHV}_{\mathrm{f}}
$$

The Wiebe function is widely used to estimate the rate of burned fuel mass in thermodynamic calcula- tions, and allows the independent input of function shape parameters $(\mathrm{m})$ and of burn duration, and represented by relation above

$$
\mathrm{x}_{\mathrm{b}}=1-\exp \left(-\alpha \cdot\left(\frac{\varphi-\varphi_{0}}{\Delta \varphi}\right)^{\mathrm{b}+1}\right)[16,29]
$$

Wiebe equation parameter $\alpha$, determining the quality of combustion, and can be written, as

$$
\alpha=\ln (1-\mathrm{x} *)=-6,908
$$

where: $x^{*}=0.999-$ value of burned fraction at the end of combustion.

In the differential form Wiebe equation, can be written as

$$
\frac{\mathrm{dx}_{\mathrm{b}}}{\mathrm{d} \varphi}=\alpha \cdot \frac{\mathrm{b}+1}{\Delta \varphi} \cdot\left(\frac{\varphi-\varphi_{0}}{\Delta \varphi}\right)^{\mathrm{b}} \cdot\left(1-\mathrm{x}_{\mathrm{b}}\right)
$$

The semi-empirical Wiebe function is characterrized by the simplicity of description and universality. In the presence of experimental data it is always possible to estimate the appropriate values of the Wiebe function parameters (Eq. 25), which allows to, provide simulation of the combustion process with required accuracy.

\section{Single-zone model}

It is a simplest TCM, that is used the basic TCM assumptions described in subchapter 2.1. In single zone models, cylinder charge is assumed to be uniform and the cylinder volume regarded as a singlezone. A single-zone model is often used if there is a need for a fast and preliminary analysis of the engine performance. However, single-zone considerations are associated with averaging temperature inside the cylinder during the combustion duration, which reduces the accuracy of the toxic emissions calculation.

This disadvantage can be eliminated by using a two-zone or multi-zone model that allows, to predict engine toxicity more accurately.

According to the assumptions of the single-zone model and the thermal balance presented on the Fig. 2 , a system of three equations for this model in the differential form can be writing, as

$$
\begin{gathered}
\frac{\mathrm{d}(\mathrm{m} \cdot \mathrm{u})}{\mathrm{d} \varphi}=\frac{\mathrm{dQ}_{\mathrm{x}}}{\mathrm{d} \varphi}-\sum \frac{\mathrm{dQ}_{\mathrm{w}}}{\mathrm{d} \varphi}-\mathrm{p} \frac{\mathrm{dV}}{\mathrm{d} \varphi}+\mathrm{h}_{\text {in }} \frac{\mathrm{dm}_{\text {in }}}{\mathrm{d} \varphi}-\mathrm{h}_{\text {out }} \frac{\mathrm{dm}_{\text {out }}}{\mathrm{d} \varphi} \\
\mathrm{p} \frac{\mathrm{dV}}{\mathrm{d} \varphi}+\frac{\mathrm{dp}}{\mathrm{d} \varphi} \mathrm{V}=\mathrm{mR} \frac{\mathrm{dT}}{\mathrm{d} \varphi}+\mathrm{m} \frac{\mathrm{dR}}{\mathrm{d} \varphi} \mathrm{T}+\frac{\mathrm{dm}}{\mathrm{d} \varphi} \mathrm{RT} \\
\frac{\mathrm{dm}}{\mathrm{d} \varphi}=\frac{\mathrm{dm}_{\text {in }}}{\mathrm{d} \varphi}+\frac{\mathrm{dm}_{\text {out }}}{\mathrm{d} \varphi}
\end{gathered}
$$




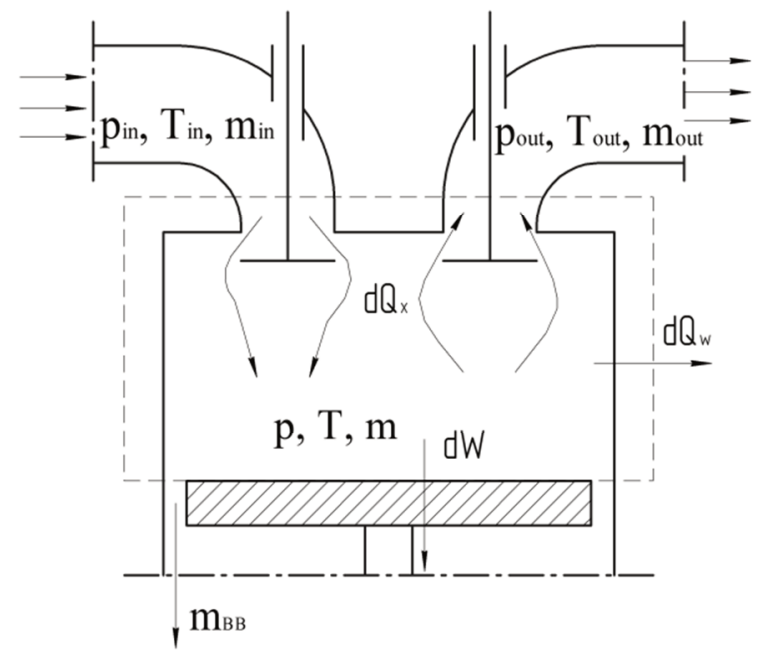

Fig. 2. Thermal balance of the single-zone model

The combustion process take place when the intake and exhaust valves are closed (closed cycle without gas exchanges), so assumed that the mass inflow equals zero $\left(\mathrm{m}_{\mathrm{in}}=0\right)$, and out flowing mass equals zero $\left(\mathrm{m}_{\mathrm{out}}=0\right)$, then Eq. 28 , can be written as follows

$$
\frac{\mathrm{d}(\mathrm{m} \cdot \mathrm{u})}{\mathrm{d} \varphi}=\frac{\mathrm{dQ}_{\mathrm{x}}}{\mathrm{d} \varphi}-\sum \frac{\mathrm{dQ}_{\mathrm{w}}}{\mathrm{d} \varphi}-\mathrm{p} \frac{\mathrm{dV}}{\mathrm{d} \varphi}
$$

If a higher accuracy in the calculation of the combustion model is needed, then blow-by mass takes into account, and then the energy balance equation, can be presented by the following equation

$$
\frac{\mathrm{d}(\mathrm{m} \cdot \mathrm{u})}{\mathrm{d} \varphi}=\frac{\mathrm{dQ}_{\mathrm{x}}}{\mathrm{d} \varphi}-\sum \frac{\mathrm{dQ}_{\mathrm{w}}}{\mathrm{d} \varphi}-\mathrm{p} \frac{\mathrm{dV}}{\mathrm{d} \varphi}-\mathrm{h}_{\mathrm{BB}} \frac{\mathrm{dm}_{\mathrm{BB}}}{\mathrm{d} \varphi}
$$

To calculate the value of the instantaneous internal energy, it is needed to determine all components in the right side in the energy conservation equation (Eq. 3). To simplify the TCM calculations, used the submodels described in the third chapter of this paper.

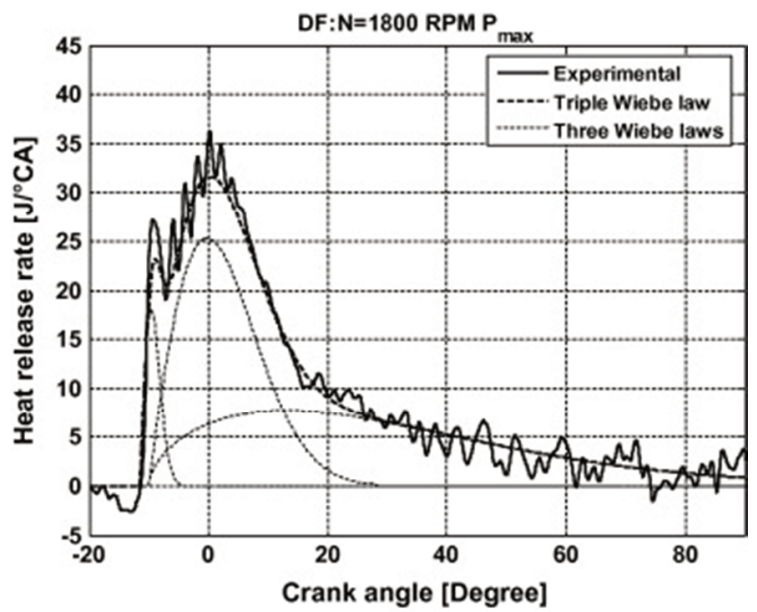

(a)

\subsection{Research carried out using the single-zone model}

The author [32] investigate the combustion process of an SI engine fuelled with methane and methanehydrogen blend. The studies were aimed to estimate the prediction accuracy of the combustion process modeling with single and double forms of Wiebe function. The results confirmed that the usage of the double Wiebe function increases the calculating accuracy. However, the difference between experimental pressure curves and simulated ones, estimated at about $3 \%$, which is caused by temperature averaging. The author [2] in order to predict the in-cylinder pressure for the diesel engine fueled by diesel and biodiesel implemented a single-zone combustion model and used the triple-Wiebe function to describe the heat release process. The simulation results are presented in Fig. 3. However, similar to the previous author, the average temperature caused differences in pressure curves, estimated at $2.5 \%$. Similar results are obtained by the authors $[20,21,25,27]$ and others.

Unlike to the previous authors, the studies of the author [13] were aimed to sensitivity analysis of the Wiebe function coefficients to the various engine loads. Moreover, method of confirming the number of combustion phases and method of estimating start angle of combustion were proposed by the authors [13].

In summary, it can be concluded that the average temperature in the cylinder does not have a significant influence over the engine performance prediction. According to the author [28] the ten percent of heat transfer prediction error leads to the order of one per cent performance prediction error [18]. A single-zone models, allows to predict the heat release rate with high accuracy. However, there are differences between experimental pressure curves and simulated ones caused by temperature averaging which is presented in Fig. 4.

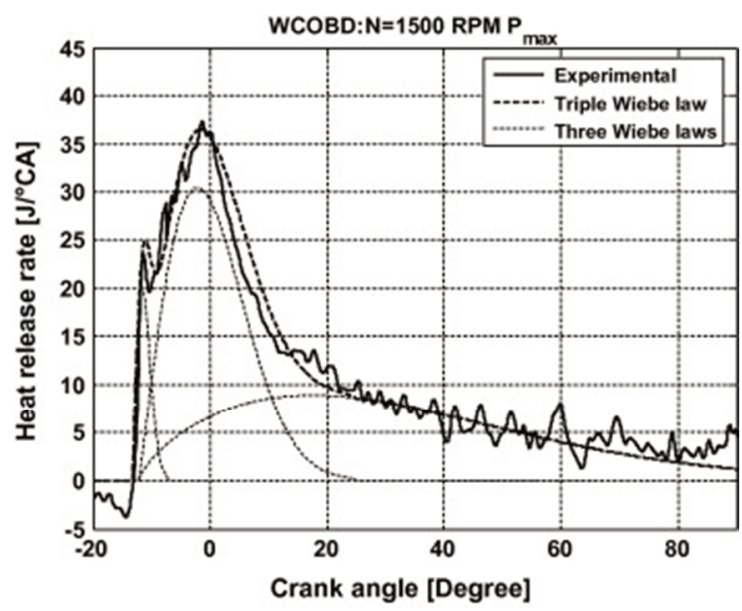

(b)

Fig. 3. HRR of the CI engine fueled with diesel (a) and biodiesel (b) [2] 

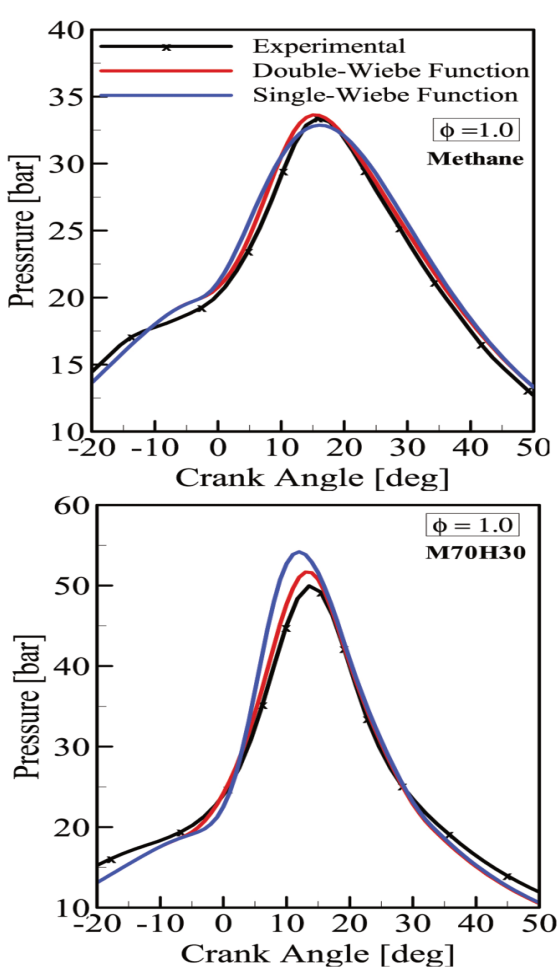

(a)
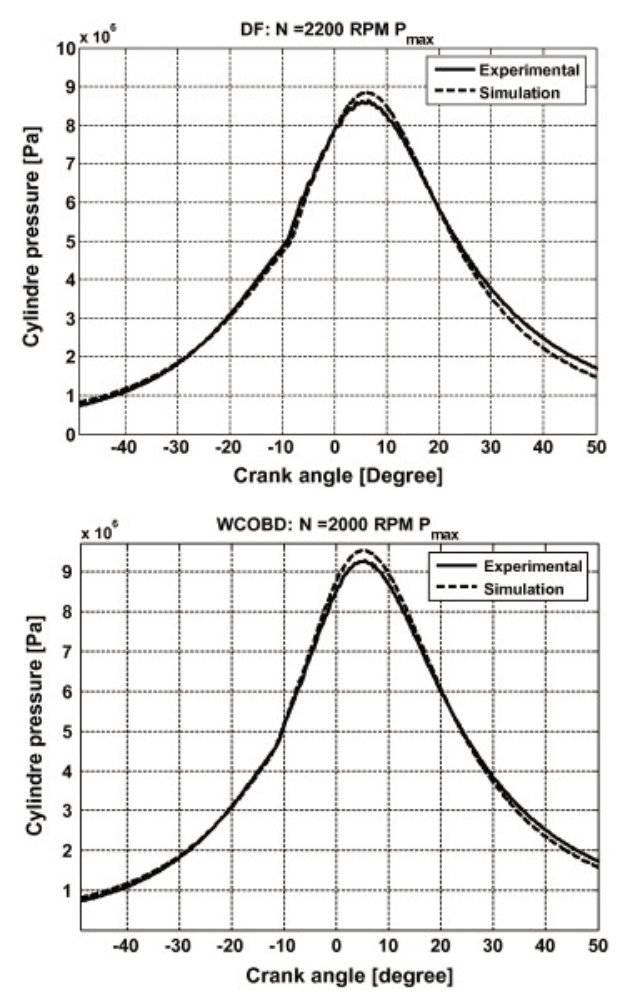

(b)

Fig. 4. Comparison of pressure development in single zone model (a) [32] and (b) [2]

\section{Two-zone model}

The two-zone combustion model is an extension of the single-zone model, which is due to its additional assumptions, gives more accurate prediction of the engine performance and toxic emission calculations.

Additional assumptions of the two-zone model:

a) The basis of the two-zone model, is the division of the cylinder volume (V) (Eq. 33) and the mass of the working fluid $(\mathrm{m})$ inside the cylinder (Eq. 34) into two zones (the unburned zone $\left(\mathrm{m}_{\mathrm{u}}\right.$ and $\left.\mathrm{V}_{\mathrm{u}}\right)$ and burned zone $\left(\mathrm{m}_{\mathrm{b}}\right.$ and $\left.\mathrm{V}_{\mathrm{b}}\right)$ ) by a thin zone of the combustion reaction (flame front), The division of the combustion chamber is shown on Fig. 5.

$$
\begin{gathered}
\mathrm{V}=\mathrm{V}_{\mathrm{u}}+\mathrm{V}_{\mathrm{b}} \\
\mathrm{m}=\mathrm{m}_{\text {fuel }}+\mathrm{m}_{\text {air }}=\mathrm{m}_{\mathrm{u}}+\mathrm{m}_{\mathrm{b}}
\end{gathered}
$$

b) The pressure inside the cylinder is uniform at any moment.

c) Each zone has its own temperature, which is uniform in its own zone. There is no heat exchange between zones.

d) Working fluid that fills the cylinder is homogeneous and contains air, fuel vapor and residual gases.

e) Each zone has its own heat transfer coefficient and contact area (with cylinder walls, cylinder head, top surface of the piston). The calculations of the contact area based on the instantaneous value of the burned mass.

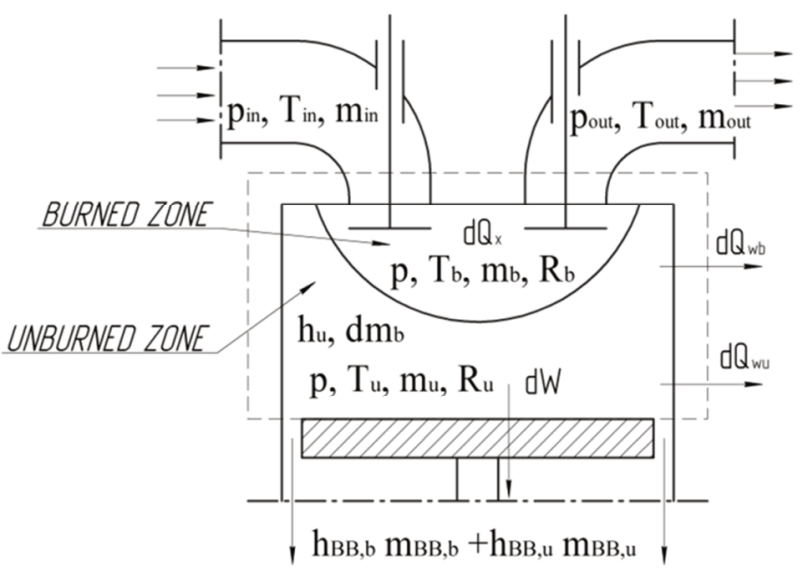

Fig. 5. Thermal balance of the two-zone model

Due to the division of the cylinder chamber into two zones, equation of energy conservation for each zone, can be written as follows:

Burned zone

$\frac{\mathrm{d}\left(\mathrm{m}_{\mathrm{b}} \cdot \mathrm{u}_{\mathrm{b}}\right)}{\mathrm{d} \varphi}=-\mathrm{p} \frac{\mathrm{dV}_{\mathrm{b}}}{\mathrm{d} \varphi}+\frac{\mathrm{dQ}_{\mathrm{x}}}{\mathrm{d} \varphi}-\sum \frac{\mathrm{dQ}_{\mathrm{wb}}}{\mathrm{d} \varphi}+\mathrm{h}_{\mathrm{u}} \frac{\mathrm{dm}_{\mathrm{b}}}{\mathrm{d} \varphi}-\mathrm{h}_{\mathrm{BB}, \mathrm{b}} \frac{\mathrm{dm}_{\mathrm{BB}, \mathrm{b}}}{\mathrm{d} \varphi}$

Unburned zone

$\frac{\mathrm{d}\left(\mathrm{m}_{\mathrm{u}} \mathrm{u}_{\mathrm{u}}\right)}{\mathrm{d} \varphi}=-\mathrm{p} \frac{\mathrm{dV}_{\mathrm{u}}}{\mathrm{d} \varphi}-\sum \frac{\mathrm{dQ}_{\mathrm{wu}}}{\mathrm{d} \varphi}-\mathrm{h}_{\mathrm{u}} \frac{\mathrm{dm}_{\mathrm{b}}}{\mathrm{d} \varphi}-\mathrm{h}_{\mathrm{BB}, \mathrm{u}} \frac{\mathrm{dm}_{\mathrm{BB}, \mathrm{u}}}{\mathrm{d} \varphi}$

$[1,14](36)$ 
In the equation above the $\mathrm{h}_{\mathrm{u}} \frac{\mathrm{dm}_{\mathrm{b}}}{\mathrm{d} \varphi}$ - includes the enthalpy flow from the unburned zone to the burned as a result of the conversion of the fresh load to the combustion products.

The ideal gas law

$$
\mathrm{p}=\frac{1}{\mathrm{~V}} \cdot\left(\mathrm{m}_{\mathrm{b}} \cdot \mathrm{R}_{\mathrm{b}} \cdot \mathrm{T}_{\mathrm{b}}+\mathrm{m}_{\mathrm{u}} \cdot \mathrm{R}_{\mathrm{u}} \cdot \mathrm{T}_{\mathrm{u}}\right)
$$

Mass conservation law

$$
\frac{\mathrm{dm}}{\mathrm{d} \varphi}=\frac{\mathrm{dm}_{\text {in }}}{\mathrm{d} \varphi}+\frac{\mathrm{dm}_{\text {out }}}{\mathrm{d} \varphi}+\frac{\mathrm{dm}_{\mathrm{BB}}}{\mathrm{d} \varphi}=\frac{\mathrm{dm}_{\mathrm{b}}}{\mathrm{d} \varphi}+\frac{\mathrm{dm}_{\mathrm{u}}}{\mathrm{d} \varphi}+\frac{\mathrm{dm}_{\mathrm{BB}}}{\mathrm{d} \varphi}
$$

\subsection{Research carried out using the two-zone model}

Due to the fact that the combustion chamber is divided into two zones, it gives a more accurate prediction of the temperature inside the cylinder. Therefore, many publications devoted to a two-zone modeling of the combustion process, except the similar issues that are also solved by single-zone modeling (presented in the $[18,26,29,31]$ and others), aimed to additional issues:

1. Analysis of the influence of the various engine operation conditions (load, rotational speed, EGR rate and others) on the emissivity and combustion characteristics. The studies of the authors [14] were aimed to predicting the effect of ethanol-gasoline (E0, E5, E10, E20, E30 and E50) fuel blends on the performance and emission characteristics of SI engine. The studies of the authors [23] were aimed to investigate and analyze the impact of the EGR rate and engine loads, on the combustion and emissions characteristics of the diesel engine by two-zone modeling.

2. Analysis the impact of different heat transfer correlations (Eq. 17, Eq. 21, Eq. 22 and others (not presented in this paper)) on the heat transfer submodel prediction and results of combustion modeling. This type of analysis was carried out by the authors [9], for study they used SI engine fueled with wet ethanol. Results showed that Hohenberg's correlation (Eq. 21) together with Wiebe function, gives the most accurate results, in the prediction of the in-cylinder pressure and heat flux through the cylinder walls (Fig. 6). A similar study was carried out on the SI engine fueled with natural gas by the authors [19]. The results shown that the Hohenberg's or Eichelberg's correlation together with Wiebe's function gives the good calculation result.

It can be concluded that, the two-zone model compared to a single-zone model allows to, additionally assess emission characteristics and analyze the heat transfer submodel, which leads to a better simulation results.

\section{Multi-zone model}

If it is needed to create the TCM with highest accuracy and lower time-consumption (compared to CFD models), more often used multi-zone models. They are an extension of the single- and two- zone models and uses the basic assumptions of single- and twozone models.

Additional assumptions of the multi-zone model:

a) The cylinder volume is divided into a predetermined number of zones (there are different ways for division some examples presented in Fig. 7 [3] and Fig. 8 [10]). The simulation results are presented in Fig. 9.

b) The pressure in each zones are the same and equal to the pressure in the cylinder.

\subsection{Baratt's multi-zone divided example}

The author [3] create a multi-zone model to analyzing the combustion process and toxic emission of a SI engine fueled with CNG.

The combustion chamber volume is divided into an unburned gas zone $\left(\mathrm{V}_{\mathrm{u}}\right)$ and a burned gas region $\left(\mathrm{V}_{\mathrm{b}}\right)$, which has been split into six 'zones' (shown in Fig.7). The numbers in the picture show each of the burned zones. In real simulations, a burned zone is generated each $5^{\circ}$ crank angle, and thus 15-20 burned zones (the exact number depends upon the combustion duration) are generally generated at the end of combustion (EOC) [3].

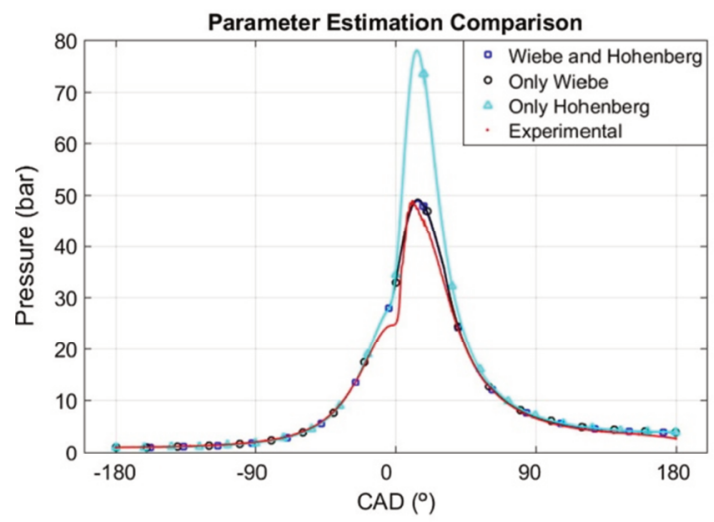

(a)

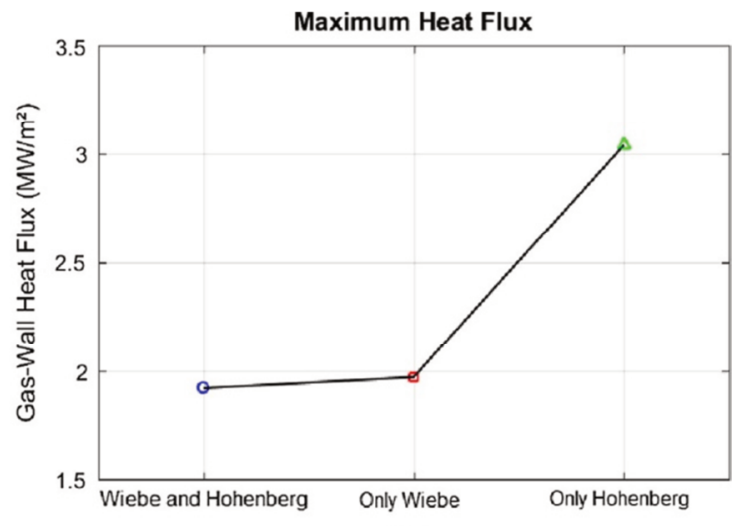

(b)

Fig. 6. Three cases estimation comparison using Hohenberg's correlation for (a) the in-cylinder pressure and (b) the maximum heat flux [9] 
The following Eq. 39 is obtained by constraining the sum of the volumes of the unburned region $\left(\mathrm{V}_{\mathrm{u}}\right)$ and of the burned zones $\left(\mathrm{V}_{\mathrm{b}, \mathrm{i}}\right.$, where subscript (i) ranges from 1 to $\mathrm{n}$ ) in order to be equal to the instantaneous cylinder volume (V) [3]

$$
\mathrm{dV}=\mathrm{dV}_{\mathrm{u}}+\sum_{\mathrm{i}=1}^{\mathrm{n}} \mathrm{dV}_{\mathrm{b}, \mathrm{i}}
$$

The mass conservation law, applied to the cylinder content, yields

$$
\mathrm{dm}=\mathrm{d}\left(\mathrm{m}_{\text {fuel }}+\mathrm{m}_{\text {air }}+\mathrm{m}_{\mathrm{r}}\right)=\mathrm{dm}_{\mathrm{u}}+\mathrm{dm}_{\mathrm{b}, \mathrm{n}}
$$

The energy conservation equation for the unburned zone and for each burned zone i, can be written, as

$$
\begin{gathered}
-q_{u} A_{u} d t+V_{u} d p=m_{u} d h_{u} \\
-q_{b, i} A_{b, i} d t+V_{b, i} d p=m_{b, i} d h_{b, i}
\end{gathered}
$$

The ideal gas law, is given by relation

$$
\mathrm{pV}=\mathrm{m}_{\mathrm{u}} \mathrm{R}_{\mathrm{u}} \mathrm{T}_{\mathrm{u}}+\sum_{\mathrm{i}=1}^{\mathrm{n}} \mathrm{m}_{\mathrm{b}, \mathrm{i}} \mathrm{R}_{\mathrm{b}, \mathrm{i}} \mathrm{T}_{\mathrm{b}, \mathrm{i}}
$$

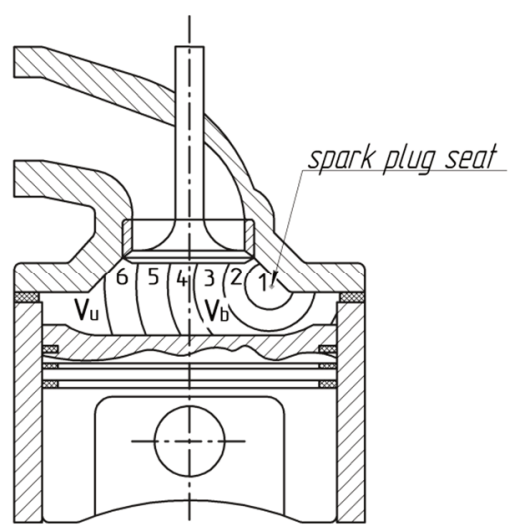

Fig. 7. Multi-zone division by Baratt [3]

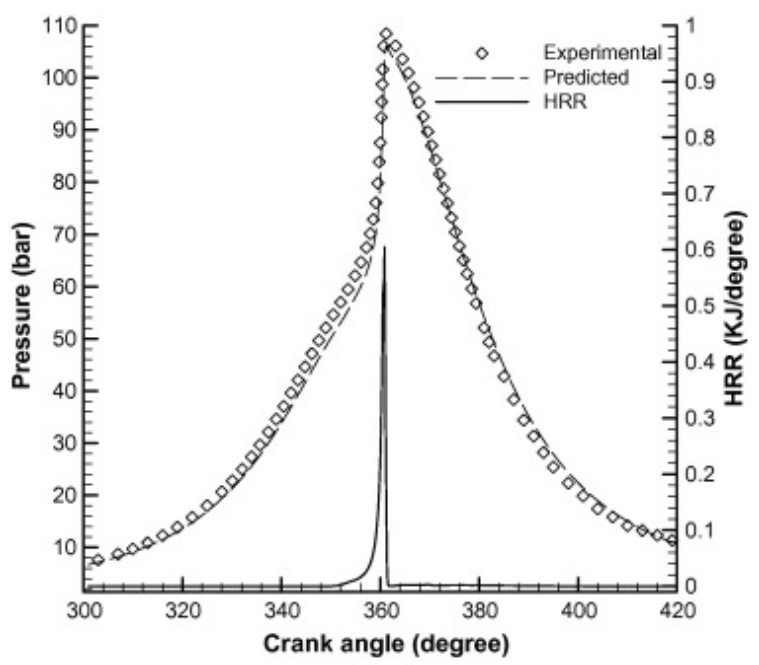

(a)
The equations of this multi-zone TCM are the same as for the two-zone model, difficulties in the equations and calculating are associated only with the increased number of zones, also in this multi-zone model is necessary to take into account heat transfer between zones.

\subsection{Fathi multi-zone divided example}

The author [10] proposed to divided combustion chamber into 13 zones, shown in Fig. 8. There is no mass transfer between zones, and the inter-zonal interactions is confined to the heat transfer between neighbouring zones and the work done due to the zonal volume changes [10].

The first law of thermodynamics for each zone in a system with a constant mass is expressed by the equation

$$
\frac{\mathrm{dU}_{\mathrm{z}}}{\mathrm{dt}}=-\mathrm{p} \frac{\mathrm{dV}_{\mathrm{z}}}{\mathrm{dt}}+\frac{\mathrm{dQ}_{\mathrm{z}}}{\mathrm{dt}}
$$

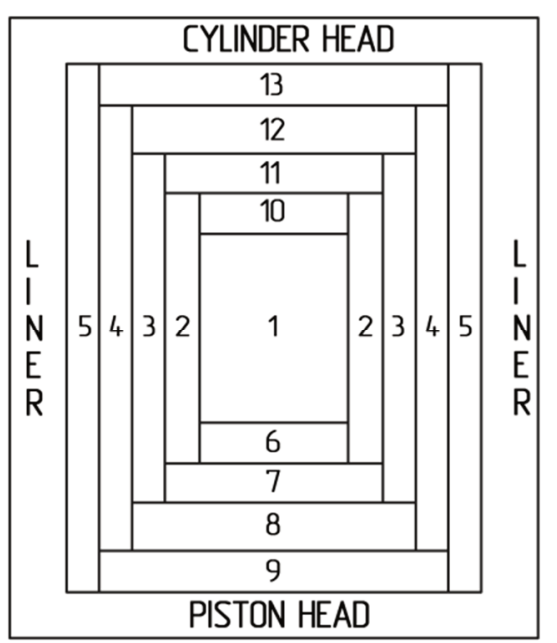

Fig. 8. Zonal configuration for multi-zone modeling [10]

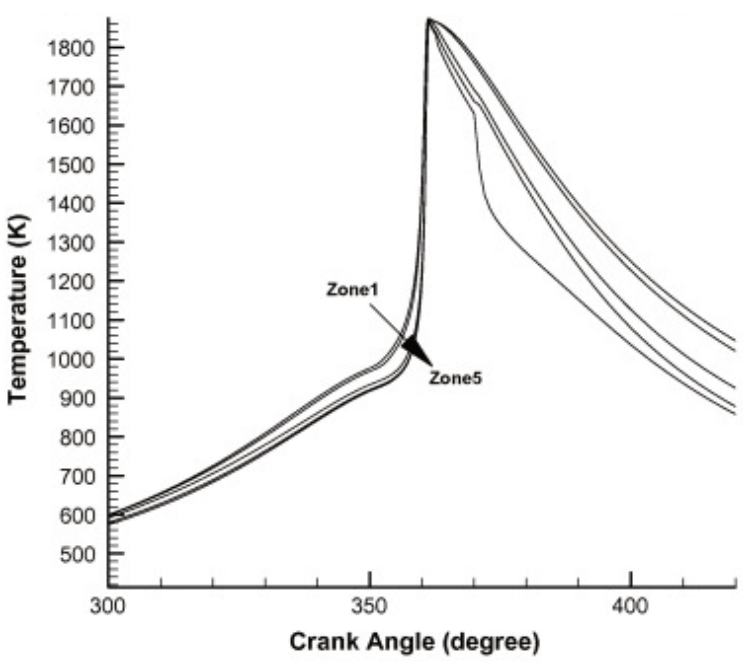

(b)

Fig. 9. In-cylinder pressure and temperature [22] 
Since all zones have a uniform pressure, total incylinder mass during multi-zone modeling is constant, mass of each zone remains constant, and the combustion chamber volume is the sum of all zones volumes, the first ordinary differential equations for the multizone model can be derived [10], as

$$
\frac{\mathrm{dp}}{\mathrm{dt}}=-\frac{1}{\mathrm{~V}^{2}} \cdot \frac{\mathrm{dV}}{\mathrm{dt}} \sum_{z=1}^{\mathrm{n}} \mathrm{m}_{\mathrm{z}} \mathrm{R}_{\mathrm{z}} \mathrm{T}_{\mathrm{z}}+\frac{1}{\mathrm{~V}} \cdot \sum_{\mathrm{z}=1}^{\mathrm{n}}\left(\mathrm{m}_{\mathrm{z}} \mathrm{T}_{\mathrm{z}} \frac{\mathrm{dR}_{\mathrm{z}}}{\mathrm{dt}}+\mathrm{m}_{\mathrm{z}} \mathrm{R}_{\mathrm{z}} \frac{\mathrm{d \textrm {T } _ { \mathrm { z } }}}{\mathrm{dt}}\right)[10]
$$

Mass conservation equation for multi-zone model is determined as follows

$$
\frac{\mathrm{dm}_{\mathrm{z}, \mathrm{i}}}{\mathrm{dt}}=\mathrm{V}_{\mathrm{z}} \mathrm{M}_{\mathrm{i}} \omega^{*}{ }_{\mathrm{z}, \mathrm{i}}
$$

Eq. 46 according to the author [10] is solved by using the Cantera chemical kinetics solver.

\subsection{Simulation results}

The multi-zone model allows to analysis incylinder temperature of different zones, which gives a positive effect on the simulation accuracy (Fig. 9).

\section{Conclusions}

All TCM overviewed in this paper are based on the differential equations of energy conservation, state and mass. All parameters of these equations, depends on the crankshaft angle or time. Therefore, this mo- dels are called zero-dimensional. TCM division is based on the number of zones inside the cylinder. The choosing of the calculation method based on the main aim and required computational accuracy of the model. However, for a numerical description of the combustion process and analysis of the impact of various engine parameters (load, rotational speed, EGR rate, etc.) on the combustion process and emission characteristics of ICE, the two-zone model is most commonly used, because it allows to predict the engine operational parameters with the required level of accuracy.

Based on the analysis of the references presented in this paper, it could be concluded that it cannot be definitely determine which correlation of the convective heat transfer coefficient gives the better results. In some cases, the heat transfer correlation gives more accurate results in other cases they cause more calculation errors. Therefore, the convective heat transfer correlation must be selected separately for each specific case.

Modeling of the combustion process by using the Wiebe's function allows to, calibrate the shape parameters and burn duration. The ability to change several parameters in one equation allows to fit them to the experimental data with the smallest errors.

\section{Nomenclature}

$\alpha$

$\alpha_{\mathrm{w}}$

$\mathrm{a}_{1}-\mathrm{a}_{7}$

$\mathrm{A}_{\mathrm{w}}$

b

B

BDC

c

$\mathrm{C}_{\mathrm{m}}$

$\mathrm{c}_{\mathrm{p}}$

CFD

dt

$\mathrm{H}$

$\mathrm{h}_{\text {in }}, \mathrm{h}_{\text {out }}$

$\mathrm{h}_{\mathrm{p}}$

ICE

1

$\mathrm{LHV}_{\mathrm{f}}$

$\mathrm{k}_{\mathrm{g}}$

$\mathrm{m}$

$\mathrm{m}_{\text {air }}$

$\mathrm{m}_{\mathrm{BB}}$
Wiebe equation parameter that determining the quality of combustion

convective heat transfer coefficient

JANAF polynomial coefficients

heat exchange area

semi empirical Wiebe equation parameter (the

Wiebe's function shape parameter)

cylinder bore

bottom dead center

Annand's correlations parameter

mean piston speed

specific heat

computational fluid dynamic

calculation step by time

change of enthalpy in- or out-flowing gas

specific enthalpy of in- or out-flowing gas

specific enthalpy

internal combustion engine

connecting rod length

lower heating value of fuel

thermal conductivity coefficient

total mass of the charge in the cylinder (air +

fuel)

mass of air

blow-by mass $m_{b} \quad$ mass of charge in-cylinder burned zone

$\mathrm{m}_{\text {fuel }} \quad$ mass of fuel

$\mathrm{m}_{\mathrm{r}} \quad$ mass of residual gas

$\mathrm{m}_{\mathrm{u}} \quad$ mass of charge in-cylinder unburned zone

$\mathrm{MW}_{\text {air }}$ molecular weight of air

$\mathrm{MW}_{\text {fuel molecular weight of fuel }}$

$\mathrm{n}$

$\mathrm{n}_{\text {air }}$

$\mathrm{n}_{\text {fuel }}$

$\mathrm{p}$

$\mathrm{p}_{\mathrm{c}}$

Q

$\mathrm{Q}_{\mathrm{w}}$

$\mathrm{Q}_{\mathrm{x}}$

$Q_{t}$

$\mathrm{q}_{\mathrm{u}} \mathrm{A}_{\mathrm{u}}$,

$\mathrm{q}_{\mathrm{b}, \mathrm{i}} \mathrm{A}_{\mathrm{b}, \mathrm{i}}$

R

r

$\mathrm{S}$

$\mathrm{S}_{\mathrm{p}}$

SI

$\mathrm{T}$ crankshaft rotation speed

number of moles of air

number of moles of fuel

in-cylinder pressure

in cylinder pressure during motor operation

total amount of in-cylinder heat

wall heat loss

heat of combustion

total thermal energy of the fuel (released during the combustion process)

moduli of the global heat transfer from the considered zone ( $u$ or $i$ ) to the adjacent zones and to the combustion chamber walls [3]

universal gas constant

crank radius (half the stroke)

entropy

instantaneous piston position

spark-ignition

in-cylinder temperature 


\begin{tabular}{|c|c|c|c|}
\hline $\begin{array}{l}\mathrm{T}_{\mathrm{w}} \\
\mathrm{TDC}\end{array}$ & $\begin{array}{l}\text { cylinder wall temperature } \\
\text { top dead center }\end{array}$ & $\mathrm{x}^{*}$ & $\begin{array}{l}\text { amount of burned fraction at the end of com- } \\
\text { bustion }\end{array}$ \\
\hline TCM & thermodynamic combustion model & $\varphi$ & crankshaft angle \\
\hline $\mathrm{U}$ & internal energy & $\tau$ & time \\
\hline $\mathrm{u}$ & specific internal energy & $\omega$ & crankshaft angular speed \\
\hline V & in-cylinder volume & $\omega^{*}$ & consumption/production rate of species during \\
\hline $\mathrm{V}_{\mathrm{b}}$ & in-cylinder burned zone volume & & combustion $[10]$ \\
\hline $\mathrm{V}_{\mathrm{u}}$ & in-cylinder unburned zone volume & $\varepsilon$ & engine compression ratio \\
\hline $\mathrm{V}_{\mathrm{c}}$ & combustion chamber volume & $\varphi$ & crankshaft angle \\
\hline W & the work on the piston & $\varphi_{0}$ & crankshaft angle of combustion start \\
\hline $\mathrm{W}$ & in cylinder gas velocity & $\Delta \varphi$ & combustion duration \\
\hline $\mathrm{x}_{\mathrm{b}}$ & burned mass fraction & & \\
\hline
\end{tabular}

\section{Bibliography}

[1] AVL. AVL-Boost Software Combustion Models, User Man., 2015.

[2] AWAD, S., VARUVEL, E.G., LOUBAR, K., TAZEROUT, M. Single zone combustion modeling of biodiesel from wastes in diesel engine. Fuel. 2013, 106, 558-568.

[3] BARATTA, M., FERRARI, A., ZHANG, Q. Multi-zone thermodynamic modeling of combustion and emission formation in $\mathrm{CNG}$ engines using detailed chemical kinetics. Fuel. 2018, 231, 396-403.

[4] BROEKAERT, S., DE CUYPER, T., DE PAEPE, M., VERHELST, S. Evaluation of empirical heat transfer models for HCCI combustion in a CFR engine. Appl. Energy. 2017, 205, 1141-1150.

[5] CLAYWELL, M. Coupled WAVE coupled WAVEVECTIS simulation of an intake simulation of an intake restricted engine.

[6] CRIPPA, M., GRANIER, C. Forty years of improvements in European air quality: regional policy-industry interactions with global impacts. Atmos. Chem. Phys. 2016. 16(6), 38253841.

[7] BIELACZYC, P., WOODBURN, J. Current directions in LD powertrain technology in response to stringent exhaust emissions and fuel efficiency requirements. 2016, 166(3), 62-75.

[8] European Parliament, Council of the European Union. Regulation (EC) No 715/2007 of the European Parliament and of the Council of 20 June 2007 on type approval of motor vehicles with respect to emissions from light passenger and commercial vehicles (Euro 5 and Euro 6) and on access to vehicle repair and mai. Off. J. Eur. Union. 2007, L171, 1-16.

[9] FAGUNDEZ, J.L.S., SARI, R.L., MARTINS, M.E.S., SALAU, N.P.G. Comparative analysis of different heat transfer correlations in a two-zone combustion model applied on a SI engine fueled with wet ethanol. Appl. Therm. Eng. 2017, 115, 22-32.

[10] FATHI, M., SOMERS, B. Stand-alone single- and multizone modeling of direct injection homogeneous charge compression ignition (DI-HCCI) combustion engines. Appl. Therm. Eng. 2017, 125, 1181-1190.

[11] GRABOWSKI, Ł., PIETRYKOWSKI, K., WENDEKER, M. AVL simulation tools practical applications. 2017. 2012.

[12] GUIZZETTI, M., ITALIA, F.A.P. Combined WAVEVECTIS simulation of an intake manifold of V6 PFI gasoline engine. 1-15.

[13] HU, S., WANG, H., YANG, C., WANG, Y. Burnt fraction sensitivity analysis and 0-D modelling of common rail diesel engine using Wiebe function. Appl. Therm. Eng. 2017, 115, 170-177.

[14] ILIEV, S.P. Developing of a 1-D combustion model and study of engine characteristics using ethanol- gasoline blends. Proc. World Congr. Eng. 2014, II, 1-6.

[15] KABANOV, O. Choosing of calculation method for heat transfer process in gas engine with spark ignition. 2012, 96-102.

[16] KAVTARADZE, R.Z. IC engines theory. Book for universities. N.E. Bauman, Moscow 2008.

[17] KÉROMNÈS, A. Internal combustion engine modeling. 2017.

[18] LOGANATHAN, S., LEENUS, J.M., NAGALINGAM, B., PRABHU, L. Heat release rate and performance simulation of DME fuelled diesel engine using oxygenate correction factor and load correction factor in double Wiebe function. Energy. 2018, 150, 77-91.

[19] LOUNICI, M.S., LOUBAR, K., BALISTROU, M., TAZEROUT, M. Investigation on heat transfer evaluation for a more efficient two-zone combustion model in the case of natural gas SI engines. Appl. Therm. Eng. 2011, 31(2-3), 319-328.

[20] MAROTEAUX, F., SAAD, C. Diesel engine combustion modeling for hardware in the loop applications: effects of ignition delay time model. Energy. 2013, 57, 641-652.

[21] MAROTEAUX, F., SAAD, C., AUBERTIN, F. Development and validation of double and single Wiebe function for multi-injection mode Diesel engine combustion modelling for hardware-in-the-loop applications. Energy Convers. Manag. 2015, 105, 630-641.

[22] NOBAKHT, A.Y., KHOSHBAKHI, S.R., RAHIMI, A. A parametric study on natural gas fueled HCCI combustion engine using a multi-zone combustion model. Fuel. 2011, 90(4), 1508-1514.

[23] RAKOPOULOS, C.D., RAKOPOULOS, D.C., MAVROPOULOS, G.C., KOSMADAKIS, G.M. Investigating the EGR rate and temperature impact on diesel engine combustion and emissions under various injection timings and loads by comprehensive two-zone modeling. Energy. 2018, 157, 990-1014.

[24] Ricardo. "Ricardo software WAVE," User Man., 2016.

[25] SHAHBAKHTI, M., KOCH, C.R. Thermo-kinetic combustion modeling of an HCCI engine to analyze ignition timing for control applications. Spring Tech. Meet. Combust. Institute/Canadian Sect. 2007, 1-7.

[26] SONG, R., SCHOCK, H. A control-oriented model of turbulent jet ignition combustion in a rapid compression machine. Proc. Inst. Mech. Eng. Part D J. Automob. Eng. 2017, 231(10), 1315-1325.

[27] SORUSBAY, C., SOYHAN, H.S. Double-Wiebe function: an approach for single-zone HCCI engine modeling. Appl. Therm. Eng. 2007, 28(11-12), 1284-1290. 
[28] STONE, R. Introduction to internal combustion engines. 3. Springer 1999.

[29] SUN, Y., WANG, H., YANG, C., WANG, Y. Development and validation of a marine sequential turbocharging diesel engine combustion model based on double Wiebe function and partial least squares method. Energy Convers. Manag. 2017, 151, 481-495.

[30] VERHELST, S., SHEPPARD, C.G.W. Multi-zone thermodynamic modelling of spark-ignition engine combustion - an overview. Energy Convers. Manag. 2009, 50(5), 1326-1335.

Denys Stepanenko, MEng. - Faculty of Mechanical Engineering, Gdansk University of Technology.

e-mail:denstepa@student.pg.edu.pl
[31] YANG, X., ZHU, G.G. A control-oriented hybrid combustion model of a homogeneous charge compression ignition capable spark ignition engine. Proc. Inst. Mech. Eng. Part D J. Automob. Eng. 2012, 226(10), 1380-1395.

[32] YILDIZ, M., ALBAYRAK ÇEPER, B. Zero-dimensional single zone engine modeling of an SI engine fuelled with methane and methane-hydrogen blend using single and double Wiebe function: a comparative study. Int. J. Hydrogen Energy. 2017, 42(40), 25756-25765.

Zbigniew Kneba, DSc., DEng. - Faculty of Mechanical Engineering, Gdansk University of Technology.

e-mail: zkneba@pg.edu.pl 